\title{
Conjugated Eicosapentaenoic Acid (cEPA) Inhibits L. donovani Topoisomerase I and has an Antiproliferative Activity Against L. donovani Promastigotes
}

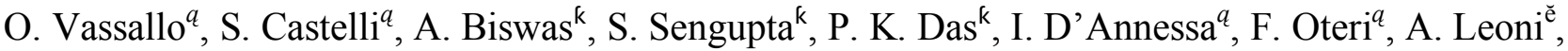 \\ P. Tagliatesta ${ }^{\breve{\mathrm{e}}}$, H. K. Majumder ${ }^{\mathrm{k}}$ and A. Desideri ${ }^{a, \xi, *}$
}

\author{
${ }^{a}$ Department of Biology, University of Rome Tor Vergata, Via Della Ricerca Scientifica, Rome 00133, Italy \\ ${ }_{\xi}^{\xi}$ Interuniversity Consortium, National Institute Biostructure and Biosystems (INBB), Rome, Italy

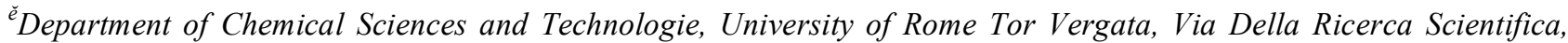 \\ Rome 00133, Italy \\ ${ }^{k}$ Infectious Diseases and Immunology Division, Indian Institute of Chemical Biology, 4, Raja S.C Mullick Road, Kolkata \\ 700032, India
}

\begin{abstract}
Conjugated eicosapentaenoic acid inhibits the relaxation activity of purified L. donovani topoisomerase I, with an efficiency higher than that displayed by the corresponding human enzyme. Docking of the acid compound over the 3D structure of the enzyme shows that the complex is stabilized by a large network of interaction between the compound and many residues located in proximity of the active site, including the catalytic tyrosine 222, providing an explanation for its efficient inhibitory effect. The acid has also a strong antiprotozoal activity against $L$. donovani promastigotes $\left(\mathrm{EC}_{50}=75\right.$ $\mu \mathrm{M})$ whilst it has no effect against murine macrophages $\left(\mathrm{IC}_{50} \sim 2 \mathrm{mM}\right)$. Taken together the results indicate that $L$. donovani topoisomerase I can be considered an interesting molecular target and that conjugated eicosapentaenoic acid can be taken in consideration as a possible lead compound against leishmaniasis.
\end{abstract}

Keywords: Conjugated eicosapentaenoic acid, leishmania donovani, omega 3 fatty acids, therapeutic index, topoisomerase I.

\section{INTRODUCTION}

The protozoan Leishmania donovani is the etiological agent of visceral leishmaniasis, a chronic parasite-borne zoonotic disease with high morbidity and mortality levels, transmitted by the bite of female sandflies [1, 2]. Leishmaniasis diseases affect around 12 million people worldwide, with two million new cases of annual incidence and 350 million at risk to be infected [3]. Since no effective vaccine has been developed at present, chemotherapy is the unique way to control a disease that may be fatal if left untreated. However at the moment the drugs available for leishmaniasis treatment are toxic, expensive and frequently ineffective $[3,4]$.

Around 25 compounds and formulations show antileishmanial effects in clinical uses [3]. Between these clinical antileishmanial drugs, the pentavalent antimonials meglumine antimoniate (Glucantime) and sodium stibogluconate (Pentostam) have been employed as first-line treatments for both Visceral (VL) and cutaneous leishmaniasis (CL) for many years, but are no longer useful against Indian Visceral leishmaniasis because of the development of resistance [5].

*Address correspondence to this author at the Department of Biology, University of Rome Tor Vergata, Via Della Ricerca Scientifica, Rome 00133, Italy; Tel: (+39) 06-72594276; Fax: (+39) 06-2023500;

E-mail: desideri@uniroma2.it
The pentavalent antimonials act upon several target that include the inhibition of parasite glucolysis, fatty acid betaoxidation, inhibition of ADP phosphorylation [6]. That class of compound it has also been reported to cause non-specific blocking of SH groups of amastigote proteins and inhibition of topoisomerase I [7]. Amphotericin B deoxycholate (Fungizone) is effective against VL but is nephrotoxic [8]. It is a good option in patient that showed resistance to treatment with antimonials. The antileishmanial activity of amphotericin B is due to its recognition of 24 substituted sterols, that increase drug selectivity towards the microorganism. At high concentration it triggers cationic and anionic influx via formation of aqueous pores resulting in cell lyses [9]. AmBisome, a liposomal formulation of amphotericin $\mathrm{B}$, is highly effective against $\mathrm{VL}$ and is less toxic than Fungizone, but is more expensive than the other current antileishmanial drugs [8]. The phospholipid analog miltefosine was registered as a novel oral treatment for VL. Although miltefosine is the first oral antileishmanial drug, its limitations include gastrointestinal tract toxicity, teratogenicity, and relatively high cost $[8,10]$. The antileishmanial mechanism of action of this compound can be extrapolated from its effect on mammalian cells, where it causes modulation of cell surface receptors, inositol metabolism, phospholipase activation, protein kinase $\mathrm{C}$ and other mitogenic pathways, eventually culminationg in apoptosis [11]. Evaluation of the in vitro susceptibilities of Indian 
L. donovani patient isolates to sodium antimony gluconate, amphotericin B, and miltefosine indicates that crossresistance may be emerging among these three drugs [12]. Paromomycin, an aminoglycoside antibiotic, is effective against a wide range of bacteria and protozoa, and was registered for the treatment of VL in India in 2006. The mechanism of action of this drug in leishmaniasis involves the inhibition of protozoan protein synthesis, leading of accumulation of abnormal initiation complex [13]. In parallel, paromomycin promotes ribosomal subunit association of both, cytoplasmatic and mitochondrial forms, following low $\mathrm{Mg}^{2+}$ concentration, induces dissociation and also cause dysfunction in respiratory systems[14]. Although it is given parenterally, low cost and high efficacy have made paramomycin a useful weapon against VL [15].

In the last years a large effort has been done to identify new drugs as well as new potential targets [3]. Among the possible molecular targets to be used in chemotherapy, topoisomerase is emerging as one of the most interesting [16-23]. DNA topoisomerases are ubiquitous enzymes that catalyze changes on duplex DNA unwinding during replication, transcription, recombination and DNA repair processes. Type I topoisomerase (topo I) induces transient single-stranded breaks of the DNA duplex forming a reversible topo I-DNA covalent complex [24, 25]. Stabilization of the cleavable complex brings cells to death and the cleavable complex formed by the human enzyme is the specific target of drugs belonging to the camptothecin family that are in clinical use in colorectal cancer and solid tumors treatment [26-30]. Most eukaryotic type IB topoisomerases are monomeric enzymes including human topoisomerase I, which is comprised of 765 amino acids (91 kDa). Interestingly, DNA topoisomerase I of the kinetoplast protozoan parasite L. donovani is an unusual bi-subunit enzyme, consisting of a large subunit $(73 \mathrm{kDa})$ and a small subunit (29 kDa) [31-33]. This makes this enzyme an interesting molecular target since it can be supposed that the structural differences can permit to develop drugs able to hit the $L$. donovani but not the human topoisomerase. As a matter of fact it has been reported that DIM (3,3_-di-indolylmethane), an abundant dietary component of cruciferous vegetables, is a potent inhibitor of $L$. donovani topoisomerase I with an $\mathrm{IC}_{50}$ of $1.2 \mu \mathrm{M}$, whilst it does not display any inhibition activity against the human enzyme [34]. In line DIM displays a strong antiproliferative effect against $L$. donovani promastigote cells $[35,36]$.

Natural compounds, such as some acetylenic fatty acids, have been shown to have a direct effect both on purified topoisomerase and in L. donovani promastigotes [37]. Recently we have shown that another fatty acid, namely conjugated eicosapentaenoic acid (cEPA) has an inhibitory effect on human topoisomerase [38] and this is likely the molecular reason it inhibits the cell growth of human tumor cell lines, while it has not effect on human fibroblast cell lines [39-41]. In this work, in order to compare similarities and differences between the human and L. donovani topoisomerase I, we have investigated the effect of cEPA on both the purified enzymes and on L. donovani promastigotes in comparison to murine macrophages.

\section{MATERIALS AND METHODOLOGY}

\subsection{Over-Expression and Purification of Recombinant Proteins and Reconstitution of Ld topoisomerase I Activity Escherichia Coli}

BL21(DE3)pLysS cells harboring pET16bLdTOP1L, and pET16bLdTOP1S described previously [31-33], were separately induced at $\mathrm{OD}_{600}=0.6$ with $0.5 \mathrm{mM}$ Isopropyl- $\beta$ D-thiogalactopyranoside for $12 \mathrm{~h}$ at $22^{\circ} \mathrm{C}$. Cells harvested from 11 of culture were lysed by lysozyme/sonication in resuspension buffer $\mathrm{A}$ (50 $\mathrm{mM}$ sodium phosphate, $\mathrm{pH} 7.8$, $150 \mathrm{mM} \mathrm{NaCl}, 10 \mathrm{mM}$ imidazole and Cocktail protease inhibitor) and then cleared by centrifugation. Supernatant containing the protein was loaded onto a $\mathrm{Ni}^{2+}-\mathrm{NTA}$ agarose column (packed volume $2 \mathrm{ml}$, Qiagen), pre-equilibrated with resuspension buffer $\mathrm{A}$. The column was washed with buffer A containing $40 \mathrm{mM}$ imidazole and was eluted in the same buffer A containing $300 \mathrm{mM}$ imidazole. The eluted fractions from LdTOP1L and LdTOP1S purifications were pooled and stored at $-70{ }^{\circ} \mathrm{C}$.

Purified LdTOP1L was mixed with purified LdTOP1S separately at a molar ratio of $1: 1$ in reconstitution buffer (50 $\mathrm{mM}$ potassium phosphate, $\mathrm{pH}$ 7.5, $0.5 \mathrm{mM}$ DTT, $1 \mathrm{mM}$ EDTA, $0.1 \mathrm{mM}$ phenylmethlysulfonyl fluoride and $10 \%$ glycerol). The mixtures were incubated overnight at $4^{\circ} \mathrm{C}$ and the reconstituted fractions were used for plasmid relaxation activity.

\subsection{Plasmid Relaxation Assay}

The type I DNA topoisomerase activity was assayed by decreased mobility of the relaxed isomers of supercoiled pBluescript $(\mathrm{SK}+)$ DNA in an agarose gel. Relaxation assay was carried out as described previously [31-33], with the enzyme incubated in the relaxation buffer $(25 \mathrm{mMTris}-\mathrm{HCl}$, pH 7.5, 5\% glycerol, $0.5 \mathrm{mM}$ DTT, $10 \mathrm{mM} \mathrm{MgCl}_{2}, 2.5 \mathrm{mM}$ EDTA and $150 \mu \mathrm{g} / \mathrm{ml} \mathrm{BSA)}$ with supercoiled pBluscript $(\mathrm{SK}+)$ DNA and $50 \mathrm{mM} \mathrm{KCl}$. The amount of DNA bands fluorescence after ethidium bromide $(0.5 \mu \mathrm{g} / \mathrm{ml})$ staining was recorded by using Gel Doc 2000 under UV illumination (BioRad-Quality-one-software).

\subsection{Synthesis of Conjugated EPA}

cEPA was prepared with some modifications of the AOAC method [42, 43]. Potassium hydroxide at a concentration of $21 \%(\mathrm{w} / \mathrm{w})$ in ethylene glycol was prepared and the $\mathrm{KOH}$ solution was bubbled for 15 min with nitrogen gas. Forty milligrams of EPA was added to $10 \mathrm{ml}$ of the $21 \%$ $\mathrm{KOH}$ solution in a test tube $(50 \mathrm{ml}$ volume $)$. The mixture was bubbled with nitrogen gas and then screw capped and allowed to stand for $5 \mathrm{~min}$ at $180{ }^{\circ} \mathrm{C}$. The reaction mixture was cooled, and $10 \mathrm{ml}$ of methanol was added. The mixture was acidified to below pH 2 with $20 \mathrm{ml}$ of $6 \mathrm{~N} \mathrm{HCl}$. After dilution with $2 \mathrm{ml}$ of distilled water, the conjugated fatty acid was extracted with $5 \mathrm{ml}$ of hexane. The hexane extract was then washed with $3 \mathrm{ml}$ of $30 \%$ methanol and with $3 \mathrm{ml}$ of distilled water before being evaporated under a nitrogen gas stream. The conjugated fatty acids were stored at $-20^{\circ} \mathrm{C}$. The purity rate of conjugated fatty acid was checked by $\mathrm{UV}-\mathrm{V}$ is spectrophotometric analysis. Spectrophotometric readings confirmed the conjugation of fatty acids with a 
yield of 28.6\% conjugated diene (Abs 235nm), 57.1\% conjugated triene (Abs $268 \mathrm{~nm}$ ), $11.1 \%$ conjugated tetraene (Abs $315 \mathrm{~nm}$ ), 3.2\% conjugated pentaene (Abs 345nm). cEPA was dissolved in dimethyl sulfoxide (DMSO) at various concentrations and stored.

\subsection{Cell Viability Test by MTT Assay}

The effect of cEPA on the viability of $L$. donovani AG83 cells and murine macrophage RAW 264.7 cells was determined by 3-(4,5-dimethylthiazol-2-yl)-2,5-diphenylterazolium bromide (MTT) assay [44]. Murine macrophage RAW 264.7 cells were cultured in RPMI 1640 medium supplemented with heat-inactivated $10 \%$ fetal bovine serum at $37^{\circ} \mathrm{C}$ in a humidified atmosphere of $5 \% \mathrm{CO}_{2} / 95 \%$ air. For the MTT dye reduction assay, cells at the exponential phase were seeded in $2 \mathrm{ml}$ steryl tube and cEPA in DMSO was added to $800 \mu$ of $\sim 5 \times 10^{6}$ macrophages $/ \mathrm{ml}$ at various concentrations from $200 \mu \mathrm{M}$ to $1 \mathrm{mM}$ in a small volume as possible to have at least $0.6 \%$ DMSO in the final volume of the sample. The treated cells were spread into 6-well plate and incubated for $24 \mathrm{~h}$. After incubation the cells were centrifuged, and the supernatant was aspirated. The cell pellet was washed with PBS (1x) twice and then finally suspended in $100 \mu$ of PBS $(1 \mathrm{x})$ in 96 -well plates. Ten microliters of MTT solution (10 $\mu \mathrm{g} / \mathrm{ml}$ ) was added in each sample of 96-well plates and samples were incubated for $4 \mathrm{~h}$. After this time, $100 \mu \mathrm{l}$ of stop solution (stock: $6.8 \mathrm{mM} \mathrm{HCl}$ in isopropanol) was added and kept for $24 \mathrm{~h}$ at room temperature. The optical density was taken at $570 \mathrm{~nm}$ on an ELISA Reader (Multiskan EX; Thermo Fisher Scientific, Waltham, MA). The same MTT dye reduction assay was performed on L. donovani AG83 promastigotes cells $\left(800 \mu \mathrm{l}\right.$ in $2 \mathrm{ml}$ steryl tube of $\sim 5 \times 10^{6}$ cell $/ \mathrm{ml}$ for each sample) that were grown at $22^{\circ} \mathrm{C}$ in M199 liquid media supplemented with $10 \%$ fetal calf serum (FCS) for 24 hours treatment using cEPA dissolved in DMSO.

The rates of cell survival are expressed as percentage of control. Standard Deviation is calculated as follow:

$$
\sigma_{\mathrm{x}}=\sqrt{\frac{\sum_{i=1}^{n}\left(x_{i}-\bar{x}\right)^{2}}{n}}
$$

where $x_{i}$ is each value measured reported as percentage of control, $\mathrm{x}$ is the mean of the points, and $\mathrm{n}$ the number of misurations.

\subsection{Molecular Docking Experiment}

Docking experiments have been carried out using as receptor the crystal structure of the LdTop1LS complex taken from the PDB structure 2B9S [45] where residues 27456 and 221-262 of the large and small subunits respectively are present. Residues missing in the crystal structure, 427430 of the large subunit, have been modeled with the program Swiss-PdbViewer v. 4.0.1 [46], and the DNA cleaved strand has been joined to obtain a non covalent complex. The GROMOS force field implemented in the program has been used to regularize the structure in order to avoid clashes. The three-dimensional structure of the cEPA compound has been designed using the program Sybyl v. 6.0 (TRIPOS, http://www.tripos.com/) and minimized in vacuum using the Powell algorithm [47] implemented in Sybyl. The receptor and the ligand structures have been prepared for the docking using the AutodockTools suite v. 4 [48], and the protein-DNA complex has been immersed in a cubic simulative box, big enough to contain it entirely. Once the structures have been prepared, 250 docking runs have been performed using the Lamarkian Genetic Algorithm [49] with the Autodock 4 program [48].

The contacts between the cEPA and the protein-DNA complex have been calculated for the complex with the lowest free energy, using a cutoff of $3.5 \AA$ for the interaction. Contacts have been calculated with an in-house modified version of the g_mindist tool, belonging to the GROMACS 3.3.3 PACKAGE [50]. Clustering of the 250 cEPA docked structures has been obtained through the g_cluster tool implemented in the GROMACS 3.3.3 PACKAGE [50], using a cutoff for the rmsd among the structures of $5 \AA$. The structures belonging to the three main clusters cover more than $90 \%$ of the total structures. Images have been obtained with the program VMD [51].

\section{RESULTS}

Conjugated eicosapentaenoic acid (cEPA) has been synthesized starting from EPA fatty acid precursor as described in materials and methodology, obtaining in the final mixture a good yield of conjugated triene form, the most efficient one against tumors [39]. The inhibitory effect of cEPA on the L. donovani topoisomerase I activity, determined by a plasmid relaxation assay, is shown in Fig. (1). The assay detects the different electrophoretic mobility of the DNA supercoiled plasmid, converted by the enzyme to its relaxed form, in presence of increasing concentrations of the compound. The data indicate that cEPA inhibits $L$. donovani topoisomerase I in a dose dependent manner (Fig. (1), lane 3-11). Some inhibition is observed at $50 \mu \mathrm{M}$ and a complete inhibition is observed at $100 \mu \mathrm{M}$. As a control it is shown the electrophoretic mobility of DNA in the absence of topoisomerase I (Fig. (1A), lane 1). Since cEPA is dissolved in DMSO, an assay of the enzyme in presence of an identical concentration of DMSO without cEPA has also been carried out, to show that it has no effect on the relaxation activity of topoisomerase I (Fig. (1), lane 2). Preincubation of the enzyme with cEPA does not change the results reported in Fig. (1), at variance on what observed with the human enzyme, where a complete inhibition was observed only after pre-incubation of cEPA with the enzyme [38].

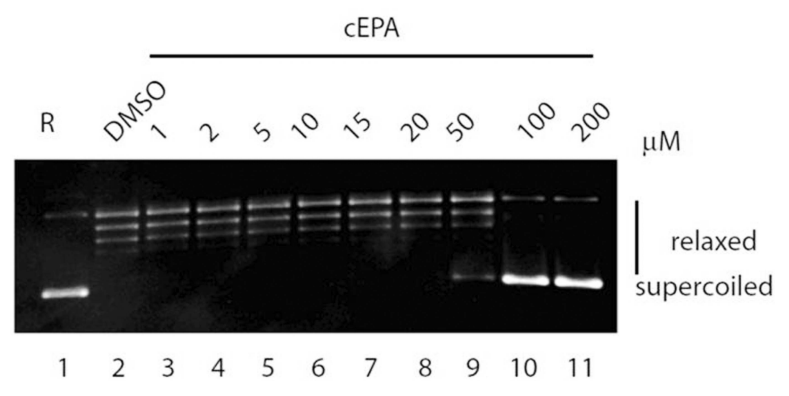

Fig. (1). Inhibition of the relaxation activity of recombinant $L$. donovani topoisomerase I by increasing concentration of cEPA (lanes 3-11). The reaction products were resolved in an agarose gel and visualized with ethidium bromide. Lane 1, no protein added. Lane 2 reaction with DNA in presence of only DMSO. The negatively supercoiled DNA substrate and the ladder of relaxed DNA topoisomers are indicated. 
The antiprotozoal activity of cEPA has been investigated measuring its toxicity against L.donovani promastigotes and as a control against murine macrophages. The results, reported in Fig. (2), indicate that cEPA starts to have an antiproliferative activity against promastigotes at $50 \mu \mathrm{M}$ and the effect is almost complete at $200 \mu \mathrm{M}$. As control it is shown that DMSO alone, the solvent where cEPA is dissolved, does not have any antiproliferative effect. At the same time cEPA does not display a real antiproliferative effect on macrophages even at a concentration as high as $1 \mathrm{mM}$.

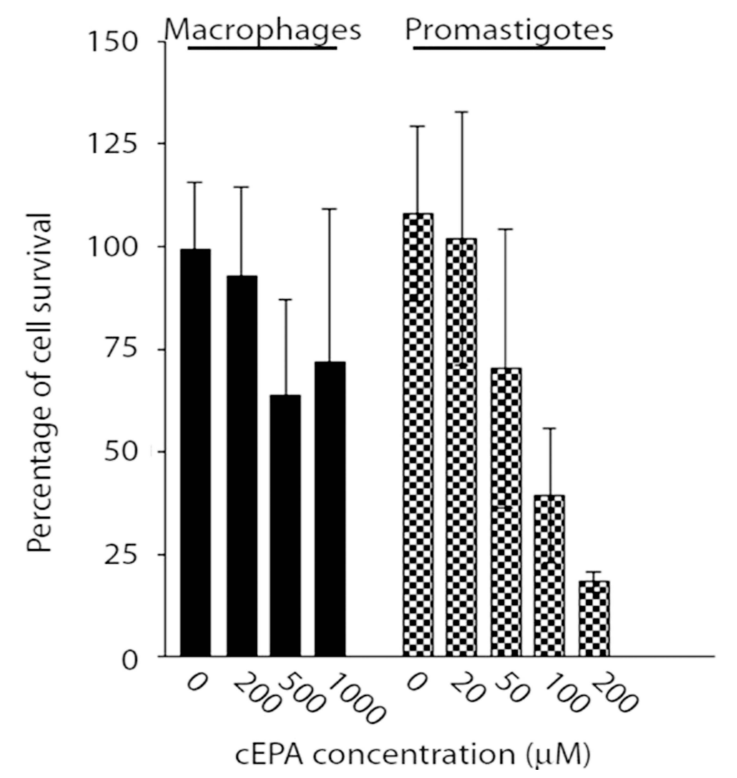

Fig. (2). Inhibition of cellular growth of murine macrophages RAW264.7 and L.donovani Promastigotes is reported using MTT assay values after $24 \mathrm{~h}$ incubation with increasing concentration of cEPA. Each value is expressed as percentage of control and repeated ( $>4$ sets). Standard deviation is calculated as shown in Materials and methods. Incubation with only DMSO is called " 0 ".

The analysis of the results, reported in Table $\mathbf{1}$, indicate that cEPA displays a good antileishmanial activity $\left(\mathrm{EC}_{50}=75\right.$ $\mu \mathrm{M})$, whilst it has no effect on macrophage $\left(\mathrm{IC}_{50} \sim 2 \mathrm{mM}\right)$, that gives rise to a therapeutic index value $\mathrm{IC}_{50} / \mathrm{EC}_{50} \sim 26$.

A docking study of cEPA on the L. donovani topoisomerase I Large sub $\backslash$ Small sub-DNA crystal structure has been performed in order to identify the interaction site. The 250 docking runs give rise to a large spread of the cEPA-protein-DNA ternary complex as shown in Fig. (3A and B). Three main clusters can be identified, on the basis of the position occupied by the compound on the receptor. In the most populated cluster, cEPA is located in proximity of the DNA minor groove and of the cap domain side of the protein. This family of structures shows an averaged free energy value of $-5 \mathrm{Kcal} / \mathrm{mol}$ Figs. (3A and $\mathbf{B}$ ). In the second cluster cEPA is located at the interface between the large and the small subunit of the protein and the averaged energy value of these complexes is $-4 \mathrm{Kcal} / \mathrm{mol}$. The third group of structures, although less populated, is characterized by a more favorable averaged free energy value of $-6.5 \mathrm{Kcal} / \mathrm{mol}$ and it contains the complex with the lowest free energy value, among all the 250 ones. In this cluster cEPA is located in proximity of the active site Figs. (3A and B). To analyze in detail the interactions occurring between cEPA and the non covalent protein-DNA complex, the structure having the lowest energy value of $-8 \mathrm{Kcal} / \mathrm{mol}$ has been selected from the third cluster Fig. (3C and D). The complex shows a large number of interactions between cEPA and both the protein and DNA. In detail, cEPA is in close contact with 9 residues, 8 of the large and 1 of the small subunit Fig. (4). In the small subunit the only contacted residue is the catalytic Tyr222. In the large subunit three residues of the catalytic pentad, Arg314, Lys352 and Arg410, interact with cEPA and interactions are also observed with Lys272 and Lys407, that correspond to Lys443, Lys587 of the human enzyme sequence. These last two residues have been shown to be involved in the interaction of cEPA with human topoisomerase IB, where cEPA inhibits the human enzyme only upon preincubation [38].

\section{DISCUSSION}

The results here presented indicate that cEPA has an anti L. donovani promastigotes effect between 50 and $200 \mu \mathrm{M}$ concentration, whilst at the same concentration the macrophages growth is unaffected Fig. (2). L. donovani promastigotes has been shown to be inhibited by fatty acids having long chain with unsaturated bonds [37], confirming that both the length and the unsaturation are important elements for antileishmanial activity of fatty acids compounds. Our experiments also indicate that the conjugation is an important element in antileishmanial activity. In line amphotericin B, that has seven conjugated double bonds, has an effect in both acute and chronic treatment stronger than mitelfosine that doesn't have any conjugate bond Table $\mathbf{1}$ [3]. It must be noted that the therapeutic index value of cEPA is pretty high, its value being at least 10 times larger than any other fatty acid, or than compounds already in

Table 1. Antileishmanial Activity of Conjugated Eicosapentaenoic Acid

\begin{tabular}{|c|c|c|c|}
\hline Compound & L. donovani Promastigotes $\mathbf{E C}_{\mathbf{5 0}}$ & Murine Macrophages IC & Therapeutic Index IC $_{\mathbf{5 0}} / \mathbf{E C}_{\mathbf{5 0}}$ \\
\hline \hline cEPA $^{\mathrm{a}}$ & $22,7 \mu \mathrm{g} / \mathrm{ml}$ & $600 \mu \mathrm{g} / \mathrm{ml}$ & 26 \\
\hline mitelfosine $^{\mathrm{b}}$ & $0.79 \mu \mathrm{g} / \mathrm{ml}$ & $1.95 \mu \mathrm{g} / \mathrm{ml}$ & 2.5 \\
\hline amphotericin B $^{\mathrm{c}}$ & $0.29 \mu \mathrm{g} / \mathrm{ml}$ & $>25 \mu \mathrm{g} / \mathrm{ml}$ & $>86$ \\
\hline
\end{tabular}

a this work

b Carballeira et al. (2009)

c Kayser et al. (2003)

$22,7 \mu \mathrm{g} / \mathrm{ml}=75 \mu \mathrm{M} \mathrm{cEPA}$

$600 \mu \mathrm{g} / \mathrm{ml}=2000 \mu \mathrm{M} \mathrm{cEPA}$ 

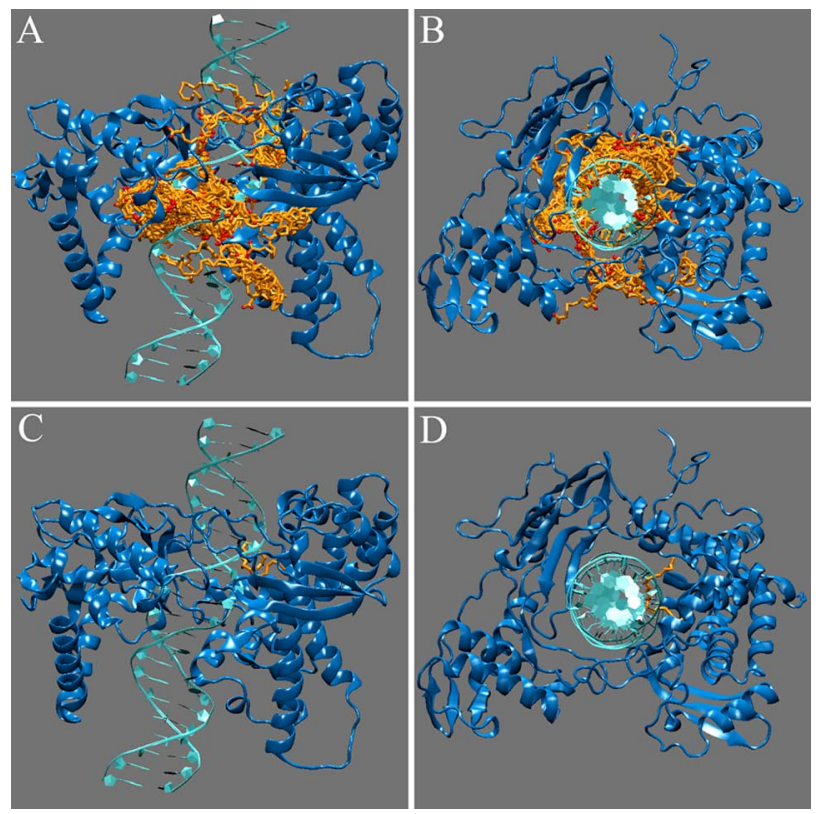

Fig. (3). (A and B) Side and upper view of the 250 cEPA docked structures on the LdTop1LS-DNA complex. (C and D) Side and upper view of the complex with the lowest free energy. In all panels the protein is represented in blue cartoon, the DNA in cyan ribbon and the cEPA compound in orange licorice with the two oxygen of the carboxyl moiety shown in red.

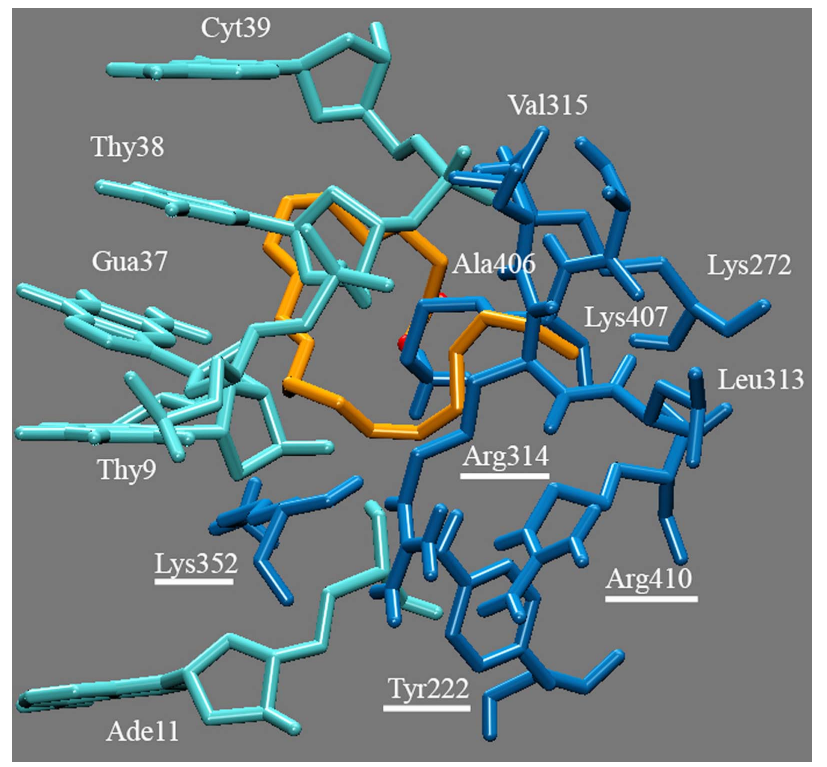

Fig. (4). Representation of the protein residues and DNA bases contacting the cEPA compound in the cEPA-protein-DNA non covalent complex having the lowest free energy. Protein residues, DNA bases and cEPA are shown in blue, cyan and orange licorice respectively. The oxygens of the carboxylic group of cEPA are also reported in red. Residues belonging to the active site are underlined by a white bar.

clinical use like mitelfosine, that has a therapeutic index of 2.5 [37], indicating that cEPA can be considered a good candidate for antileishmanial therapy. In this context, it must to be noted that cEPA synthesis is simple and that its chemical precursor EPA (from omega 3 fatty acid series) has a large natural abundance, being found in red and green algae and in fish oil [39-41].

This work also demonstrates that cEPA is an efficient inhibitor of L. donovani topoisomerase suggesting that the enzyme could be the molecular target of this fatty acids. cEPA has been shown to interact with human topoisomerase, however in the case of the human enzyme complete inhibition was never observed when DNA, enzyme and cEPA were mixed together up to $300 \mu \mathrm{M}$ cEPA concentration [38], whilst in the case of $L$. donovani topoisomerase complete inhibition is observed at $100 \mu \mathrm{M}$ Fig. (1). For the human enzyme fully inhibition is only observed upon preincubation of the enzyme with cEPA [38]. Docking of cEPA with the leishmanial enzyme has shown that the compound is able to directly interact with the catalytic Tyr222 and with several residues located in proximity of the active site Fig. (4). This strong interaction, and in particular that with the catalytic Tyr222, provides an explanation for the fact that cEPA is more efficient in inhibiting the leishmanial than the human enzyme. Indeed, it has been proven that interaction of cEPA with the human topoisomerase-DNA complex involves the contact of the compound with only three residues in proximity of the active site [38]. These results emphasize the fact that cEPA has a different interaction mechanism with human and $L$. donovani topoisomerase indicating that $L$. donovani topoisomerase can be an important new target and that the structural differences between the L. donovani and human enzymes can be exploited to develop target specific drugs. In this regard, it is to be considered that cEPA, due to its very low toxic effects for host cells [39], may be a candidate also for treatment of chronic visceral leishmaniasis.

\section{CONCLUSION}

The results indicate that cEPA inhibits more efficiently $L$. donovani than human topoisomerase, strongly interacting with the catalytic tyrosine 222 residue as shown by docking experiments. Moreover it has an antiproliferative effect against promastigotes but not against macrophages suggesting that it can be an interesting compound to be taken in consideration against leishmaniasis. It is to be noted that while the therapeutic options for treatment of visceral leishmaniasis have improved over the last decade, there is still a need for an oral agent to safeguard against the expanding resistance problem, to be used in a combinated therapy. In this contest the low toxicity is a primary requisite and cEPA has this propriety. cEPA could represent an oral agent to be given in combination with paromomycin that is now a parenterally administered. Another interesting propriety displayed by cEPA is its multi-conformational binding ability, due to the presence of the fatty acidic tail as shown by docking experiments, that would reduce the possibility of raising resistance due to the mutation of some specific residues. This profile can reduce the resistance appearance, making cEPA a promising antileishmanial drug.

\section{ACKNOWLEDGEMENTS}

F.O. and O.V. thank FILAS for a fellowship under the project "Caratterizzazione di Principi Attivi, di Origine 
Naturale e non, per Patologie Tumorali, Cardiovascolari e Infettive".

\section{REFERENCES}

[1] Murray HW, Berman JD, Davies CR, Saravia NG. Advances in leishmaniasis. Lancet 2005; 366: 1561-77.

[2] Vannier-Santos MA, Martiny A, De Souza W. Cell Biology of Leishmania spp.: invading and evadAmphociling. Curr Pharm Des 2002; 8: 297-318.

[3] Monzote L. Current Treatment of Leishmaniasis: A Review. Open Antimicrob Agents 2009; 1: 9-19.

[4] Monzote L. A review of anti-parasitic patents (1988-2008) Recent Pat Antiinfect Drug Discov. 2008; 3: 177-91.

[5] Richard JV and Werbovetz KA. New antileishmanial candidates and lead compounds. Curr Opin Chemical Biol 2010; 14: 1-9.

[6] Chakraborty AK, Majumder HK. Mode of action of pentavalent antimonials: specific inhibition of type I DNA topoisomerase of the Leihmania donovani. Biochem Biophys Res Commun 1988; 152: 605-11.

[7] Wyllie S, Cunningham ML, Fairlamb AH. Dual action of antimonial drugs on thiol redox metabolism in the human pathogen Leihmania Donovani. J Biol Chem 2004; 279: 39925-32.

[8] Olliaro P, Sundar S. Anthropometrically derived dosing and drug costing calculations for treating visceral leishmaniasis in Bihar, India. Trop Med Int Health 2009; 14: 88-92.

[9] Ramos H, Valdivieso E, Gamargo M, Dagger F, Cohen BE. Amphotericin B kills unicellular Leihmania by forming aqueous pores permeable to small cations and anions. J Membr Biol 1996; 152: 65-75.

[10] Berman J. Development of miltefosine for the leishmaniases. Minirev Med Chem 2006; 6:145-151.

[11] Verma NK, Dey CS. Possible mechanism of miltefosine-mediated death of Leihmania Donovani. Antimicrob Agents Chemother 2004; 48: 3010-5.

[12] Kumar D, Kulshrestha A, Singh R, Salotra P. In vitro susceptibility of field isolates of Leishmania donovani to miltefosine and amphotericin B: correlation with sodium antimony gluconate susceptibility and implications for treatment in areas of endemicity. Antimicrob Agents Chemother 2009, 53:835-838.

[13] Sundar S, Chakravarty J. Paromomycin in the treatment of leishmaniasis. Expert Opin Invest Drugs 2008; 17: 787-94.

[14] Maarouf M, de Kouchkovsky Y, Brown S, Petit PX, Robert-Gero $\mathrm{M}$. In vivo interference of paromomycin with mitochondrial activity of Leishmania. Exp Cell Res 1997; 232: 339-48.

[15] Sundar S, Agrawal N, Arora R, Agarwal D, Rai M, Chakravarty J. Short-course paromomycin treatment of visceral, leishmaniasis in India: 14-day vs 21-day treatment. Clin Infect Dis 2009; 49: 914-918.

[16] Das A, Dasgupta A, Sengupta T, Majumder HK. Topoisomerases of kinetoplastid parasites as potential chemotherapeutic targets. Trends Parasitol 2004; 20: 381-87. Review.

[17] Das BB, Sen N, Dasgupta SB, Ganguly A, Das R, Majumder HK. Topoisomerase research of kinetoplastid parasite Leishmania, with special reference to development of therapeutics. Indian J Med Res 2006; 123: 221-32. Review.

[18] Ganguly A, Das B, Roy A, et al. Betulinic acid, a catalytic inhibitor of topoisomerase I, inhibits reactive oxygen species-mediated apoptotic topoisomerase I-DNA cleavable complex formation in prostate cancer cells but does not affect the process of cell death. Cancer Res 2007; 67: 11848-58.

[19] Cheesman SJ. The topoisomerases of protozoan parasites. Parasitol Today 2000; 7: 277-281. Review.

[20] Boege F, Straub T, Kehr A, et al. Selected Novel Flavones Inhibit the DNA Binding or the DNA Religation Step of Eukaryotic Topoisomerase I. J Biol Chem 1996; 271: 2262-70.

[21] Fortune JM, Osheroff N. Merbarone inhibits the catalytic activity of human topoisomerase IIalpha by blocking DNA cleavage. J Biol Chem 1998; 273: 17643-50

[22] Bridewell DJ, Finlay GJ, Baguley BC. Differential actions of aclarubicin and doxorubicin: the role of topoisomerase I. Oncol Res 1997; 9: 535-42.

[23] García-Estrada C, Prada CF, Fernández-Rubio C, Rojo-Vázquez F, Balaña-Fouce R. DNA topoisomerases in apicomplexan parasites: promising targets for drug discovery. Proc Biol Sci 2010; 277 : $1777-87$.
[24] Champoux JJ. DNA topoisomerases: structure, function, and mechanism. Annu Rev Biochem 2001; 70: 369-413.

[25] Nitiss JL, Wang JC. Mechanisms of cell killing by drugs that trap covalent complexes between DNA topoisomerases and DNA. Mol Pharmacol 1996; 50: 1095-102.

[26] Basili S, Moro S. Novel camptothecin derivatives as topoisomerase I inhibitors. Expert Opin Ther Pat 2009; 19: 555-74. Review.

[27] Weekes J, Lam AK, Sebesan S, Ho YH. Irinotecan therapy and molecular targets in colorectal cancer: a systemic review. World J Gastroenterol 2009; 15: 3597-602. Review.

[28] Kimura T, Kashiwase S, Makimoto A, et al. Pharmacokinetic and pharmacodynamic investigation of irinotecan hydrochloride in pediatric patients with recurrent or progressive solid tumors. Int J Clin Pharmacol Ther 2010; 48: 327-34.

[29] Temkin SM, Yamada SD, Fleming GF. A phase I study of weekly temsirolimus and topotecan in the treatment of advanced and/or recurrent gynecologic malignancies. Gynecol Oncol 2010; 117: 473-76.

[30] Yuuki S, Komatsu Y, Fuse N, et al. Modified irinotecan/ fluorouracil/ levoleucovorin therapy as ambulatory treatment for metastatic colorectal cancer: results of phase I and II studies. Clin Drug Investig 2010; 30: 243-49.

[31] Das BB, Sengupta T, Ganguly A, Majumder HK. Topoisomerases of kinetoplastid parasites: why so fascinating? Mol Microbiol 2006; 62: 917-27. Review.

[32] Das BB, Sen N, Ganguly A, Majumder HK. Reconstitution and functional characterization of the unusual bi-subunit type I DNA topoisomerase from Leishmania donovani. FEBS Lett 2004; 565: $81-88$.

[33] Das BB, Sen N, Dasgupta SB, Ganguly A, Majumder HK. Nterminal region of the large subunit of Leishmania donovani bisubunit topoisomerase $\mathrm{I}$ is involved in DNA relaxation and interaction with the smaller subunit. J Biol Chem 2005; 280: 16335-44.

[34] Gong Y, Firestone GL, Bjeldanes LF. 3, 3 -diindolylmethane is a novel topoisomerase II alpha catalytic inhibitor that induces Sphase retardation and mitotic delay in human hepatoma HepG2 cells. Mol Pharmacol 2006; 69: 1320-27.

[35] Roy A, Das BB, Ganguly A, et al. An insight into the mechanism of inhibition of unusual bi-subunit topoisomerase I from Leishmania donovani by 3,3'-di-indolylmethane, a novel DNA topoisomerase I poison with a strong binding affinity to the enzyme. Biochem J 2008; 409: 611-22.

[36] Roy A, Ganguly A, Dasgupta SB, et al. Mitochondria-dependent reactive oxygen species-mediated programmed cell death induced by 3,3'-diindolylmethane through inhibition of F0F1-ATP synthase in unicellular protozoan parasite Leishmania donovani. Mol Pharmacol 2008; 74: 1292-307.

[37] Carballeira NM, Cartagena MM, Prada CF, Rubio CF, BalañaFouce R. Total synthesis and antileishmanial activity of the natural occurring acetylenic fatty acids 6-heptadecynoic acid and 6icosynoic acid. Lipids 2009; 44: 953-61.

[38] Castelli S, Campagna A, Vassallo O, et al. Conjugated eicosapentaenoic acid inhibits human topoisomerase IB with a mechanism different from camptothecin. Arch Biochem Biophys 2009; 486: 103-10.

[39] Igarashi M, Miyazawa T. Do conjugated eicosapentaenoic acid and conjugated docosahexaenoic acid induce apoptosis via lipid peroxidation in cultured human tumor cells? Biochem Biophys Res Commun 2000; 270: 649-56.

[40] Yonezawa $\mathrm{Y}$, Hada $\mathrm{T}$, Uryu $\mathrm{K}$, et al. Inhibitory effect of conjugated eicosapentaenoic acid on mammalian DNA polymerase and topoisomerase activities and human cancer cell proliferation. Biochem Pharmacol 2005; 70: 453-60.

[41] Yonezawa Y, Hada T, Uryu K, et al. Mechanism of cell cycle arrest and apoptosis induction by conjugated eicosapentaenoic acid, which is a mammalian DNA polymerase and topoisomerase inhibitor. Inter J Oncol 2007; 30: 1197-1204.

[42] Association of Official Analytical Chemists. Acids (polyunsaturated) in oil and fats. In: Helrich K, Ed. Official methods of analysis of the association of official analytical chemists. Arlington: Association of Official Analytical Chemists 1990; 960-3.

[43] Pitt GAJ, Morton RA. Prog Chem Fats Other Lipids 1957; 4: 227-78. 
[44] Mosmann T. Rapid colorimetric assay for cellular growth and survival: application to proliferation and cytotoxicity assays. J Immunol Methods 1983; 65: 55-63.

[45] Davies DR, Mushtaq A, Interthal H, Champoux JJ, Hol WG. The structure of the transition state of the heterodimeric topoisomerase I of Leishmania donovani as a vanadate complex with nicked DNA. J Mol Biol 2006; 357: 1202-10.

[46] Guex N, Peitsch MC. SWISS-MODEL and the Swiss-PdbViewer: an environment for comparative protein modeling. Electrophoresis 1997; 18: 2714-23.

[47] Powell MJD. An Efficient Method for Finding the Minimum of a Function of Several Variables without Calculating Derivatives. Comput J 1964; 17: 155-62.
[48] Morris GM, Huey R, Lindstrom W, et al. AJ. AutoDock4 and AutoDockTools4: automated docking with selective receptor flexibility. J Comput Chem 2009; 30: 2785-91.

[49] Morris GM, Goodsell DS, Halliday RS, et al. A.J. Automated docking using a Lamarckian genetic algorithm and an empirical binding free energy function. J Comput Chem 1998; 19: 1639-62.

[50] Lindahl E, Hess B, van der Spoel D. GROMACS 3.0: A package for molecular simulation and trajectory analysis. J Mol Mod 2001; 7: 306-17.

[51] Humphrey W, Dalke A, Schulten K. VMD: visual molecular dynamics. J Mol Graph 1996; 33: 27-28.

(C) Vassallo et al.; Licensee Bentham Open.

This is an open access article licensed under the terms of the Creative Commons Attribution Non-Commercial License (http:/creativecommons.org/licenses/ by-nc/3.0/) which permits unrestricted, non-commercial use, distribution and reproduction in any medium, provided the work is properly cited. 